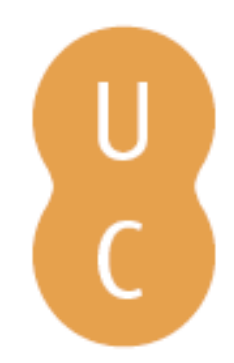

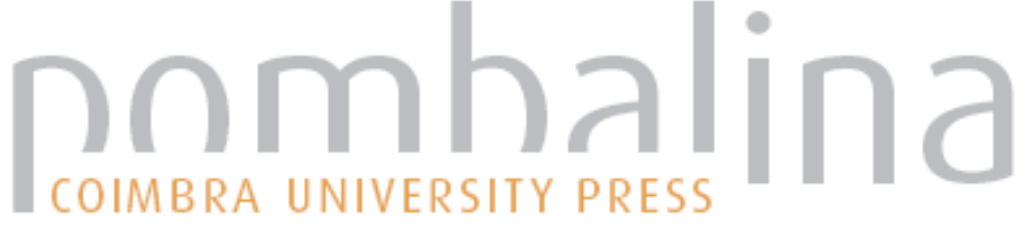

\section{Poéticas da comunicação: literatura tradicional oral e rap}

Autor(es): Mourão, José Augusto

Publicado por: Imprensa da Universidade de Coimbra

URL

persistente:

URI:http://hdl.handle.net/10316.2/36643

DOI:

DOI:http://dx.doi.org/10.14195/978-989-26-0873-0_4

Accessed : $\quad$ 26-Apr-2023 12:19:21

A navegação consulta e descarregamento dos títulos inseridos nas Bibliotecas Digitais UC Digitalis, UC Pombalina e UC Impactum, pressupõem a aceitação plena e sem reservas dos Termos e Condições de Uso destas Bibliotecas Digitais, disponíveis em https://digitalis.uc.pt/pt-pt/termos.

Conforme exposto nos referidos Termos e Condições de Uso, o descarregamento de títulos de acesso restrito requer uma licença válida de autorização devendo o utilizador aceder ao(s) documento(s) a partir de um endereço de IP da instituição detentora da supramencionada licença.

Ao utilizador é apenas permitido o descarregamento para uso pessoal, pelo que o emprego do(s) título(s) descarregado(s) para outro fim, designadamente comercial, carece de autorização do respetivo autor ou editor da obra.

Na medida em que todas as obras da UC Digitalis se encontram protegidas pelo Código do Direito de Autor e Direitos Conexos e demais legislação aplicável, toda a cópia, parcial ou total, deste documento, nos casos em que é legalmente admitida, deverá conter ou fazer-se acompanhar por este aviso.

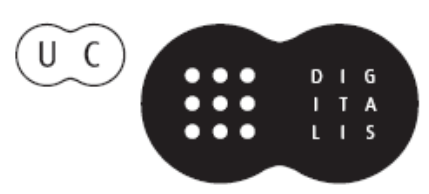


www.uc.pt/ imprensa_uc CONTACTO imprensa@uc.pt VENDAS ONLINE http://livrariadaimprensa.uc.pt JANEIRO 2015
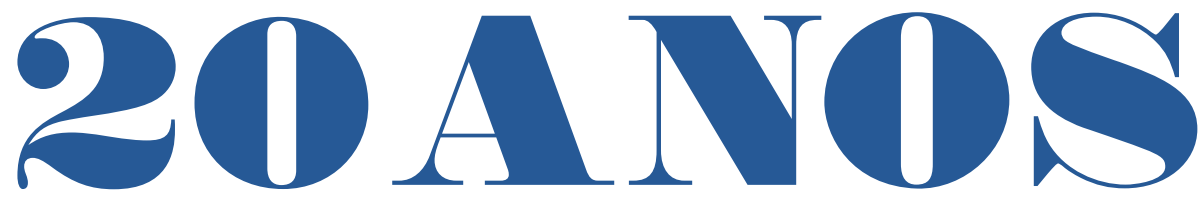

\section{DE JORNALISMO CONTRA A INDIFERENÇA}

TEXTOS DE

Marc Lits, Adriano Duarte Rodrigues, Tito Cardoso e Cunha, José Augusto Mourão, Alberto Pena Rodríguez, Maria Augusta Babo, Daniel Cronu, João Pissarra Esteves, Gilles Gauthier, Heloísa Paulo e Luís Reis Torgal, Alfredo Barroso, António Fidalgo, Nöel Nel, João de Almeida Santos, Juan Luis Cebrián, António Dias Figueiredo, Marina Themudo, Jorge Sampaio, Nelson Traquina, Mário Soares
( livro que agora se apresenta, nasce de dois desígnios fundamentais: por um lado, celebrar duas décadas de ensino do Jornalismo na Universidade de Coimbra e, por outro, partilhar com um público mais alargado um conjunto de reflexões sobre os media, o jornalismo, a comunicação e o espaço público.

Se o ensino superior do Jornalismo em Portugal, relativamente tardio em relação ao resto da Europa, deu os seus primeiros passos no fim dos anos 70 do século passado, ele aparece apenas duas décadas depois na academia coimbrã. Contudo, esta foi, no contexto nacional, a primeira licenciatura em Jornalismo, distinguindo-se, quer em título, quer em objetivos, das licenciaturas então existentes no país. A criação de uma Licenciatura em Jornalismo na Universidade de Coimbra, em 1993-1994, foi, por si, um acontecimento. Com efeito foi necessário que reitor, professores e jornalistas ousassem atualizar a oferta curricular da Faculdade de Letras, oferecendo um curso há muito desejado pela sociedade e pelo mercado, embora desconsiderado por alguns setores da academia. Correndo o risco de omitir alguém, a quem antecipadamente pedimos desculpa, não podemos deixar de recordar os esforços dos jornalistas João Mesquita, João Fonseca, em representação
Todas as gerações, sem dúvida, se julgan para refazer o mundo. A minha sabe, nc que não poderá refazê-lo. A sua tarefa é tc

Consiste em impedir que se desfaça, $p$ unicamente das suas negações A. Camus, Discursos da Suécia (1957)

do Sindicato dos Jornalistas, e de Jorge Castilho, a quem mais tarde se viria associar o nome de Mário Martins, bem como o do então Reitor da Universidade de Coimbra Rui Alarcão, e dos professores João Roque e Luís Reis Torgal. Entre 1993 e 1996, a Licenciatura em Jornalismo funcionou com um Secretariado, que teve um papel executivo e científico nos primeiros tempos do curso na FLUC. Presidido pelo Presidente do Conselho Científico Ludwig Scheidl, este 


\title{
Poéticas da Comunicação: Literatura Tradicional Oral e Rap
}

\author{
José Augusto Mourão
}

Universidade Nova de Lisboa

O pós-modernista prefere as palavras ao silêncio,

o logocentrismo ao taoismo.

D. Fokkema

A poesia é assim a prosa feita música, ou a prosa cantada.

F. Pessoa

The wider universalization of music, the proliferation of styles, and a democratization of the music-making process, are all analogous to what happened at the dawning of the 'Gutenberg era'.

Don Ihde

A literatura (oral/escrita) tem mais a ver com técnicas de transformação da linguagem do que com a expressão de sentimentos. Por isso a tarefa da poética é descrever e explanar as formas características da comunicação poética, pronunciar-se sobre os modos de existência de objetos verbais identificados como literários, sejam eles definidos como objetos técnicos ou como objetos estéticos.

Tentarei cotejar a figura do cantador na literatura tradicional oral e o rapper enquanto figuras definidas no interior de poéticas da comunicação que partilham entre si procedimentos comuns, visando embora finalidades diferentes. Entre a "cantoria”, a "embolada" e o rap há evidentes conexões semântico-cognitivas e pragmáticas. Um "gaio excesso" liga estes "signos em rotação" no mar da "semiose ilimitada" em que cada literatura é uma ilha.

Determinante nos dois casos é o suporte somático dos textos que, cantados ou recitados, remetem sempre para situações performativas, dispositivos enunciativos em que são convocados os "públicos", as circunstâncias, os tempos da enunciação, os deíticos. Como sabia um mestre da literatura oral: o que for que o texto dito ou cantado evoque, pelo seu processo linguístico,

\footnotetext{
* Texto de publicação póstuma.
} 
a performance impõe-lhe um referente global relacionado com o corpo. É pelo corpo que somos tempo e lugar: a voz, nossa emanação, proclama-o.

\section{A comunicação poética}

Como se distingue a comunicação poética de outros tipos de comunicação? Os Formalistas Russos e os estruturalistas de Praga distinguem ações baseadas numa total compreensão do segmento de realidade envolvida e ações que envolvem uma seleção de detalhes, essencial para o sucesso dessa mesma ação. No primeiro caso, basta reconhecer a informação dada. A relação do agente com a realidade é automatizada; os objetos do mundo tornam-se entidades abstratas definidas unicamente pelo contexto funcional no qual desempenham os seus papéis limitados. As ações comunicativas simplificam a relação do agente com a realidade, não a obscurecem nem a complicam. O desejo de completo sucesso num ato de comunicação força os interlocutores a concentrarem-se em determinadas características da situação e a negligenciar outras. A desautomatização de uma relação com um parceiro de comunicação é menos difícil do que a desautomatização de uma relação com a realidade que se tornou automatizada através do uso constante do mesmo código, dado o pressuposto de que "tudo tende a fazer sistema”. Todo o sistema de normas socioculturais inclui sanções contra possíveis infrações do código moral, como observa Posner, as ações comunicacionais como as ações não comunicacionais só podem ser desautomatizadas se elas próprias forem deslocadas uma vez mais, num contrato em que não lhes é permitido serem de novo automaticamente realizadas. Quando lemos uma notícia de um jornal, uma receita de culinária, etc., construímos o significado do texto em conformidade com o que Siegfried J. Schmidt chama a convenção F (convenção de congruência com os factos). Quando, porém, lemos um poema ou um romance, construímos o significado dos textos lidos de acordo com uma outra convenção, a convenção $\mathrm{E}$ (convenção de estética), segundo o mesmo autor. Na leitura destes textos suspendemos a convenção F, deixando de relacionar as suas asserções com seres, objetos e estados de coisas empiricamente existentes e aceitando convenções e normas que são válidos no âmbito da estética.

Só a linguagem poética tem o poder de desautomatizar o seu uso corrente. Um maço de cigarros vazio no chão, ou um pedaço de jornal velho, são, normalmente, lixo. Mas se esse maço estiver colado ao jornal e ambos estiverem encaixilhados numa moldura pendurada na parede de uma galeria de arte, tornam-se arte. Greimas, no livro admirável que é De l'Imperfection, fala de fra- 
turas, de dessimetrias. A dessimetria, o inesperado vem sempre do contraste entre o que aparece e o que vem simulado - efeito surpresa. Mas é G. Genette quem melhor condensa a poética jakobsoniana: a recorrência textual (similaridades formais desdobradas no espaço do texto) induz uma espécie de recorrência paralela ao nível do significado, que é a metáfora metonimizada: similaridades de sentido manifestadas no espaço do conteúdo (volume simbólico a três dimensões que se estabelece no poema e que, por assim dizer, o constitui: malha horizontal de equivalências significantes (fónicas, métricas, gramaticais, entonacionais, prosódicas) que remetem para uma outra malha horizontal de equivalências semânticas de cada forma para cada sentido (diagramas). A função poética consiste na relação da mensagem consigo própria. Na comunicação estética, isso é manifestamente importante; no exemplo dado, a função metalinguística da moldura enfatiza a função poética da relação estética entre o maço de cigarros e o jornal. Mas Jakobson afirma que esta função opera também na conversa normal. Jakobson usa o slogan político "I like Ike" para ilustrar a função poética. Três monossílabos, cada um deles com o ditongo "ai". Dois deles rimam. Usam apenas duas consoantes. E tudo isso faz um slogan fácil de fixar e agradável ao ouvido. A linguagem poética tende, portanto, a tornar-se opaca. Nem se anula diante do objeto, nem se limita a traduzir os sentimentos do autor: torna-se a si própria objeto. Autotélica. Enquanto a linguagem corrente é o sinal de uma realidade que a ultrapassa, a linguagem poética significa-se a si própria. A sua opacidade é o equivalente da sua densidade de existência, do seu volume de linguagem. Por outras palavras, a linguagem poética faz-nos escutar o dizer no dito, a enunciação no enunciado, levando-nos a perceber a linguagem na sua ação, na sua performatividade. O poema é de uma solidez icónica, não de signo.

\section{O cantador}

Nem o rap nem a literatura tradicional oral podem ser definidos como códigos puramente convencionais, imediatamente reconhecíveis. Aos tipos extremos de códigos convencionais podem chamar-se estéticos, mais difíceis de definir porque mais variados, mais afetados pelo seu contexto cultural. Neles, as descodificações aberrantes são a norma. Expressivos, estes códigos englobam o mundo interior, subjetivo. Já os códigos arbitrários e lógicos são, em grande parte, referenciais. Os códigos estéticos podem desempenhar todas as funções de Jakobson; os códigos estéticos convencionais permitem o acordo entre os seus utentes através de uma experiência cultural partilhada. A arte de massas e a arte popular usam códigos estéticos convencionais. Só 
que, como observa J. Fiske, os códigos estéticos, da mesma forma que seguem as convenções, também as podem quebrar: a arte inovadora contém em si mesma pistas ou indícios que apontam para a sua própria descodificação... Numa sociedade de massas, com produção e consumo em massa, a obra de arte única adquire um estatuto adicional pela sua própria unicidade.

\section{O cantador}

Repare-se nas expressões que utiliza o cantador. Para ele não apenas “o cantar também hora”, como ele canta "p'ra dar que falar”, “p'ra cegar os olhos” a quem não o pode ver, 'p'ra fazer ráivar'. Cite-se, a respeito da intenção de agir cantando, de convencer pelo palavreado, o trabalho minucioso de bordadeira de textos que é Ana Paula Guimarães: Numa cultura em que a oralidade assume papel preponderante, o despique retórico estrutura a relação entre dois cantadores em situação de desafio mútuo, desenvolvendo-se ao longo do tempo. Diga-se uma palavra sobre o cruzamento da figura do cantador, comum à cultura portuguesa e ameríndia. Ignora-se se os ameríndios tinham uma poética declamatória, independente da produção destinada à música. Fernão Cardim, em janeiro de 1584, escrevia que homens e mulheres, "juntos andam correndo toda a povoação, dando grandes urros, e juntamente vão bailando, e cantando ao som de um cabaço cheio de pedrinhas. Vão tão serenos e por tal compasso que não erram ponto com os pés, e calcam o chão de maneira que fazem tremer a terra... Estas trovas fazem de repente, e as mulheres são insignes trovadoras. O “desafio" português, duelo poético, fixou-se no Brasil seguindo o processo do acompanhamento musical. Só no nordeste o canto é independente do acompanhamento musical. Os instrumentos tocam exclusivamente nos intervalos das sextilhas, quando ninguém está cantando. A voz humana soa isolada durante todo o combate. Os poetas improvisadores, conhecidos como cantadores ou repentistas, famosos em todo o sertão brasileiro, lembram a tradição do duelo verbal que data dos gregos e dos romanos. O cantador de despique é tido por "armador" de cantigas, do mesmo modo que o rapper. Uma diferença notável os separa desde já: no "desafio" não há dança que envolva a solidariedade do auditório nem resposta coral. A curiosidade fixava, com redobrada atenção, durante dias, o evoluir dessa pugna verborum. No rap, as diferenças entre "head music" e "body music", como diferença entre música composta e música espontânea parecem não ter qualquer pertinência. Não há sentir sem saber-fazer. O envolvimento do corpo e a resposta do corpo do público são fundamen- 
tais para esta poética: "D.J.K.G.B. dá-lhe com a alma/agora quero saber se estão a gostar/Se a resposta é sim quero ver as mãos no ar/” (Black Company).

\section{O Rapper}

O rap é um género de música popular com raízes nas subclasses negras da sociedade americana, nascido no final dos anos 70; um símbolo sonoro da luta de classes, quando os DC começaram a virar as agulhas para a realidade do Bronx. Este tipo de música, que pretende mudar o mundo, é definida nos anos 80 por Chuck D., líder dos Public Enemy como a "CNN da América Negra”. Arte do tempo, de feitura singular, sobre um esperanto sonoro. Gabriel, o Pensador pertence à humanidade, mas porque é, antes de mais, um rapper brasileiro, na sua intensidade e na sua respiração. Junta-se um arcaísmo bruto e uma sofisticada técnica, combinando o "hip hop" com o património brasileiro e uma pilha de "samplers", de Milton Nascimento a Rita Lee e outra pilha de "samplers" americanos. Esta arte tecnológica tem o condão de aliar o ruído universal, numérico, arte da cabeça que põe o resto do corpo na gaveta ao trabalho do corpo sobre um material. Antes de mais, revela-nos um conflito de estéticas: modernista (racionalista, formalista) e pós-modernista (irracionalista), retomando a tradição da inflexão oral dentro das vanguardas no Brasil ("Capoeira" de Oswaldo de Andrade), na esteira de Augusto dos Anjos ou de Arnaldo Antunes. De resto, como nota Haroldo de Campos, é com Gregário, com sua poesia da "função metalinguística" e da "função lúdico-poética", com a sua poética da "salvação através da linguagem» (Wisnik), que "sincronizam" e "dialogam" o João Cabral, engenheiro de poemas combinatórios, ou a vanguarda, que, já em 1955, propugnava por uma "obra de arte aberta" e por um "neo--barroco". É com Gregório de Matos, a "língua ferina” baiana, que Gabriel dialoga, prosseguindo o mesmo sentimento de missão e a mesma "dialética da malandragem".

O empurrão decisivo na divulgação do rap em Portugal veio com o álbum de Gabriel, o Pensador. Referir-me-ei aqui à primeira coletânea de música rap feita entre nós, Rapública, um projeto que conta com seis bandas nacionais, editado este ano pela Sony Music, com formas de expressão do tipo. "O rap é a poesia de rua, onde se usa um discurso com tomates, direto, sem floreados”, afirma Pacman, membro da Weasel”. Trata-se de facto de um fenómeno sociocultural e de uma expressão artística que obriga a analisar vários tipos de problemas, como por exemplo os da rejeição, da integração e da canonização. Mas antes de mais vejamos em que medida se distingue a sua comunicação poética de outros tipos de comunicação. 
A tradição poética está ligada ao improviso, ao ritmo e à comunidade. Na literatura tradicional oral e no rap. Assim se compreende o carácter coletivo, improvisador e fortemente ritmado do "rap". É como um recitativo, uma quasemelodia, e isso constitui uma transformação do poético em si mesmo. Há um abismo entre a inevitável mediação verbal e a imediatidade do mundo numa poética em que a palavra, com a sua cor e a sua sonoridade desempenha um papel essencial. O grão da voz de que a "rouquidão" é o veículo, testemunha dessa violência da voz que se quer fazer ouvir. Mas o rap atesta também uma forma de interesse da juventude pelos acontecimentos políticos e sociais da sua vida. Positivo, portanto, enquanto não está ao serviço da publicidade. $\mathrm{O}$ mundo da publicidade, que se tornou intertexto generalizado, açambarca e põe ao seu serviço aquilo a que chamamos poesia - os jogos de palavras, a rapidez das paronímias, as paranomásias, etc. A palavra poética pensante não é económica nem comunicacional. Consideremos o rap como um signo, um qualisigno, melhor, cuja ocorrência se faz através da repetição-ritmo ou ritournello. É o regresso duma intensidade constitutiva do signo que não é pensável sem a ideia de hábito e de meio. Entenda-se meio a representação de uma diferença, uma ordem de conformidade sobre a qual contamos para agir. Reagir é captar, interpretar o signo, desenvolvê-lo. O rap marca também o regresso do corpo à linguagem. A representação desencarna o corpo, separa-o daquilo que ele pode. O corpo que o rap toca é certa maneira de afetar e de ser afetado, de sentir e de ser sentido.

\section{Arte ou técnica?}

A questão de saber se o rap é uma arte é a mesma que se põe a qualquer outro objeto "artístico": para que um objeto possa entrar no mundo da arte bastará um dizer com autoridade institucional, ou é necessário algo de prévio que assegure o valor performativo desse dizer (Arthur Danto)? O pós-modernismo recusará decerto a distinção entre arte e técnica como distinção anacrónica. Tchernychewsky, o chefe de fila do niilismo em matéria estética, denuncia, bem antes de Bourdieu, as componentes ideológicas dos valores estéticos. A obra de arte é dessacralizada. O niilismo toma agora formas lúdicas. A condição humana deixou de ter qualquer sentido. Nestas canções faladas, escandidas, passa apenas o vento do quotidiano, a irreverência dos costumes. Tudo deflui da poética do roubo: o sample é feito de amostras, extratos diversos recortados, roubados de discos existentes. Letras banais, estúpidas, dicção má. Refrãos repetitivos, rudes, obscuros, sem os grandes guarda-chuvas do Ideal e do Sacrifício. 
O código fónico-rítmico, no quadro do sistema modelizante secundário, mantém primordial relação de interdependência com o código métrico, manifestando por vezes relações importantes com o código estilístico (fono -iconismo) e com o código que regula os valores semânticos e pragmáticos dos textos literários, em correlação com a conceção do mundo modelizada nesses textos e com a função que lhes é atribuída numa determinada situação histórico-social (o ritmo, v.g. de um texto de combate ideológico-cultural - A cena do ódio de Almada). É evidente que o código métrico está ligado ao semântico-pragmático do policódigo literário e aos sistemas semióticos que configuram a ideologia de uma dada comunicação social'.

O rap é fundamentalmente uma técnica de mistura que depende fundamentalmente do virtuosismo criador do rap do DJ, o qual opera, seguindo a ordem: cortar, misturar, frasear, arranhar.

Donde a ambiguidade desta técnica como poética. E da própria denominação dos rappers, mais operadores do que criadores. A formalização dos sons sintéticos, o material de fabricação standard, implica uma distância (remote control), um uso em detrimento do sentido. O hip hop ou acid jazz são componentes audíveis em toda a parte, sem fronteiras. O que era jazz transformou-se em hip hop, uma música próxima do espírito da rua, do improviso e da vanguarda que marcava o jazz antes de se tornar num museu de cera comercial. Por outro lado, o que faz viver uma forma poética é um público de primeiro grau convidado a expressar-se: "venha-se expressar". O que é aqui primordial é o ouvido, fusional, tátil. Triunfo do corpo e da oralidade. O hip hop vive na veia, na mente, na frente, nas costas, no peito. Para Abrunhosa, que não se considera um rapper, mas que recorre a elementos do rap, o "Socorro" tem o mesmo beat dos passos. Porque "todos temos um ritmo cardíaco próprio e um ritmo de passo próprio". "Socorro" está na volta dos 120 bpm (beat per minute), que é mais ou menos o seu ritmo de passo. O rap tem um estilo semiótico em que são dominantes traços aspetuais, tensivos que acompanham as modalizações nos dispositivos usados. Há que ter em conta, na modulação coerente que este estilo apresenta, fenómenos rítmicos, aspetuais, quantitativos, e sobretudo o tempo. Isto porque o carácter de forma rítmica está ligado à nossa perceção quantitativa do tempo. Só há Gestalt quando uma determinada correlação temporal se pode encontrar entre os diferentes elementos que compõem a forma. É necessária uma geometria subjacente,

\footnotetext{
${ }^{1}$ Vitor Manuel Aguiar e Silva, Teoria da Literatura, 4 a ed., 1984, Coimbra, Almedina, p. 100.
} 
mais exatamente uma cronometria, para definir formas iguais ou semelhantes, escreve R. Thom².

- Traços Tipicamente pós-modernos do rap: apropriação, "seleção", discurso informal, "causette", babelizar, misturar, aglutinar, estandardizar. O hip hop, ritmo funky, rock, disco.

a. contestação do ideal tradicional da originalidade, romântico;

b. contestação do ideal da unidade, da integridade da obra que professa o modernismo que voltou o texto para dentro de si próprio, até ao "absoluto do texto";

c. prática da fragmentação, da colagem (funky collage), do laboratório;

d. a apropriação, o roubo, a reciclagem, a fagocitação, substituem a obsessão da originalidade e a angústia da influência;

e. a ideia do ritual de legitimação substitui a ideia fetichista da obra de arte "pura", acompanhada agora da dessacralização de todas as superstições literárias;

f. o gosto de arte pobre;

g. inversões, indireções semânticas;

Leite de Vasconcelos, analisando o princípio de composição das cantigas, para além da estruturação formular, económica, presente na redondilha maior, refere o emprego de "neumas", "palavras meramente fónicas, sem sentido, apenas para satisfazerem o ritmo"3. A utilização de "versos comuns em assuntos diferentes", versos bordões, repetições de palavras ou de versos para conseguir encher o quadro" no primeiro dístico da quadra popular, serve para apoiar o cantador improvisador, dando tempo à invenção-recriação do segundo dístico eventualmente mais adequado à situação em questão... Os moldes estão quase sempre feitos"4.

\section{Arte pós-moderna}

O pós-modernismo é de facto o código dominante na literatura ocidental desde os anos cinquenta, sem que tenham desaparecido da prática discursiva outras manifestações da literatura, outros sociocódigos. A grande diferença entre modernistas e pós-modernistas parece estar na estratégia adotada relativamente ao universo de crença e ao tipo de racionalidade que se pratica. Se o modernista defende os seus próprios juízos de valor, o pós-

${ }^{2}$ René Thom, Apologie du Logos, Paris Hachette, 1990, p. 123.

${ }^{3}$ José Leite de Vasconcelos, Introdução de Pedro Fernandes Thomaz, Cantigas Populares da Beira, $2^{\mathrm{a}}$ Ed. Coimbra, Imprensa da Universidade, 1923, p. XXI.

${ }^{4}$ CPPIII, 214. 
-modernista não vê razões para os privilegiar, porque não discrimina, não pretende entronizar o intelectual, em tempo de secularização. Ao nível das convenções que afetam a técnico-composição do pós-modernismo algo nos separa do modernismo. O final múltiplo, a destruição da ideia de conexão, o fragmento, o inventário (Borges), a duplicação, sugerem o mínimo de legibilidade, de inacabamento, de arbitrariedade, de labirinto, de desgaste semântico (Handke).

\section{O poder das palavras}

O primeiro modelo poético da nossa tradição cultural, via Homero, não é o discurso, mas o “oceano das palavras”, essencialmente oral. Gabriel afirma trazer uma nova linguagem e uma nova forma de comunicação. A poética entende-se como um certo modo/estilo de pensamento que tenta manter as coisas à distância. $\mathrm{O}$ rap vive contraditoriamente entre a crença no poder da palavra e algumas das formas da herança nihilista. A palavra é uma arma e ao mesmo tempo pode-se nada dizer. "Pôr o nada em palavras" dizia S. Beckett. "Words, words...” queixava-se já Shakespeare. Na Cantora Careca de Ionesco os atores proferem banalidades sem conta, num tom o mais convencido possível. Encenação de uma estética da banalidade que produz uma espécie de semipatologia em estética: é pelo prazer que o nada é introduzido no dizer. O ludismo, a impotência metamorfoseia-se em criação. "Nós temos o poder de abalar", diz Gabriel, um "inconformado sem partido”. Ou então, em Portugal, na opinião de Jay Jay Neige, da Weasel: "Decidimos usá-la (cantar em português) porque lhe reconhecemos vantagens: o calão e as asneiras têm muita força e as letras são logo catapultadas". Logo na introdução de "Pé na Tchôn, Karapinha no Céu”, General D aponta que vai falar: "Nunca hei-de-de deixar que ninguém me tire o direito de falar”. Revendo, muito rapidamente, a forma do conteúdo dos dois álbuns evocados, o de Gabriel, o Pensador, e o de Rapública, vamos reencontrar um denominador comum a estes projetos a mesma luta contra a intolerância, a mesma denúncia das injustiças, a mesma doutrinação social e a mesma militância. Denúncia do xenofobismo radical, inconformismo, liberdade de expressão, apelo a vir tomar a palavra, necessidade de que o jogo mude de cor: "Isto vai ter que mudar", são estas as formas mais recorrentes do rap. A sua componente catártica, salvífica, não é menos evocada: "Mas o rap me salvou” (Putos da rua). Não se esquece a guerra (em Angola, Croácia e Somália) nem a pergunta que o salmista diante do niilismo dominante fazia: "Onde para Deus?"(Salmo 42,4; 79,10). 
A retórica, como o demonstra Protágoras, visa, não a verdade, mas a eficácia prática. Há rappers que se autoapresentam como "professores da verdade", o que é ainda a forma como os retóricos se apresentavam. "Prophets of the city". Que profetas e que verdade? Verdade pragmática? "Não temos dinheiro mas da voz fazemos nossa arte", "As lanças estão quebradas mas a voz ainda vinga”, "dum jogo de palavras faço a minha arte" (Boss AC). A palavra, a voz, é tudo o que resta a estes "inconformados sem partido", mas que contam também com um Large Professor. Mesmo se "eles dizem as coisas como se fosse um sermão", acusa Nuno Carneiro, porta-voz dos Mind Da Gap, menos crente na "salvação através da linguagem".

O campo literário tinha os seus guardas, a sua censura, as suas fronteiras. Ruíram as fronteiras dos géneros, ruíram as fronteiras da própria Literatura. A arte tornou-se um processo, um produto, e não apenas uma criação. O objeto literário é definido como objeto técnico. Vejam-se as recentes declarações de Pierre Alfieri e Olivier Cadiot na apresentação da "Revue de Littérature Générale: O objetivo não é voltar a dar à escrita as suas "lettres de noblesse", mas subtraí-las aos critérios que regulam a sua crítica e a sua produção: Produtos Industriais de Ficção ou Artesanato Local de Poesia"s.

Acentuou-se o lado da participação lúdica e da criatividade, quebrando-se a ideia de um espectador desligado, preso apenas à frieza do "oeil sec" (Descartes) e da "frieza burguesa" (Adorno). A teoria catártica (Spencer) decorre do conceito formulado por Schiller segundo o qual o formal do jogo seria a liberdade de uma superabundância de energia. No contexto da arte contemporânea, participação designa a relação entre o espectador e a obra de arte acabada, ao passo que a interação implica uma relação recíproca entre o espectador e um sistema inteligente. Esta ideia de interação pode ser vista como extensão do conceito de frio de McLuhan, que o utilizou para caracterizar os media da era eletrónica que se distinguem pelo maior envolvimento sensorial, exigindo um esforço maior de interpretação e de participação porque fornecem menor quantidade de informação ou uma informação disseminada. O rap suscita do espectador uma resposta polisensorial total, essencialmente lúdica. Desapareceu o seu lado monumental, imperecível. A cultura dos mass media é tecnológica, comercial, existindo apenas num contexto real, local, de ghetto, como acontece ao rap, vivendo da exaltação alucinatória do sublime pós-moderno ou tecnológico. É difícil estabelecer

${ }^{5}$ Revue de Littérature Générale, n. ${ }^{\circ}$ 1. Edições P.O.l., 1995. 
a diferença entre o que seria o rap comercial e o rap progressista, "underground". A suspeita incide inteiramente sobre a impostura dos media. Há, evidentemente que ter em conta, senão o desaparecimento, pelo menos o eclipse daquilo a que depois de Mme de Stäel se chamou "literatura", que de objeto literário se está transformando em objeto tecnológico. A literatura tradicional oral esteve sempre mais próxima do lado mecânico, monótono, da comunicação estética, privilegiando muito mais o código técnico-formal, geralmente pobre (vejam-se os códigos rimático e métrico) do que o código semântico. Nisto, o rap mantém com ela uma estreita conivência. A estrutura estética pode incluir além da mensagem, outros fatores de comunicação: o plano comportamental do destinador, a resposta experienciada por determinados grupos de destinação, o mecanismo do mercado, e por vezes os segmentos tematizados de realidade (v.g. John Cage e Andy Warhol). A escola de Tartu (especialmente Y. Lotman) foi a primeira a integrar estes fatores no interior do modelo multinível e a chamar a atenção para níveis semióticos não-linguísticos em que se podem fundar as realizações de códigos socioculturais. Esta é uma indicação clara de que é preciso ter em conta, ao abordar a literatura tradicional oral ou o rap, não apenas os códigos representativos mas também os códigos apresentativos que fazem parte do seu "radical de apresentação".

A produção poética popular/tradicional/oral vive da repetição, do já dito/ ouvido, sabido. A generatividade deste tipo de literatura não é a do código técnico-formal em que se inscreve, mas a da circunstância. Como observa Walter Ong, "as sociedades orais vivem principalmente num tempo presente que mantém o equilíbrio ou homeostasia libertando-se das memórias que deixam de ser relevantes"

O recitador ou o rapper recompõem, atuam sobre a matéria precedente dada, sob o olhar/ouvido do público e dos contextos que esses, sim, exigem uma palavra, uma batida nova, com evidentes efeitos nos processos de composição. A poesia, que era revelação do sentido do mundo, tomou-se, por sua própria culpa, insociável nas suas experimentações de vanguarda que só levaram à rarefação do público. A poesia é responsável pelo isolamento a que se condenou. O rap, mais do que a literatura tradicional oral - tudo o que é tradicional parece ter já morrido - é uma das palavras que restam, um certo modo ou estilo do pensamento que se ocupa da experiência humana e que

${ }^{6}$ Walter Ong, Orality and Literacy. The technologizing of the world, London, New York, Methuen, 1982, p. 46. 
tenta manter a violência das coisas à distância. O que implica outra dimensão referencial, o afastamento operado pela palavra poética no respeito por aquilo que se chama "a realidade" e sem reivindicar qualquer autonomia formalista do poema, qualquer cedência ao cultural que é a acomodação entre o consumo e a arte (Deguy). A menos que a cultura seja o que resiste à comunicação e à pedagogia, precisando delas para definir os seus lugares e modos de resistência. Tal como a arte se faz com a cultura e contra a cultura. O rap representa a transformação do poético em si mesmo. Representará também o fim da revelação do sentido do mundo que competia à poesia? 